\title{
EFISIENSI KLASIFIKASI BIG DATA MENGGUNAKAN IMPROVED NEAREST NEIGHBOR
}

\author{
Aditya Hari Bawono', Ahmad Afif Supianto \\ ${ }^{1,2}$ Fakultas Ilmu Komputer, Universitas Brawijaya \\ Email: ${ }^{1}$ ndaimen@ub.ac.id, ${ }^{2}$ afif.supianto@ub.ac.id
}

(Naskah masuk: 13 Juni 2019, diterima untuk diterbitkan: 07 November 2019)

\begin{abstract}
Abstrak
Klasifikasi adalah salah satu metode penting dalam kajian data mining. Salah satu metode klasifikasi yang populer dan mendasar adalah k-nearest neighbor $(\mathrm{kNN})$. Pada $\mathrm{kNN}$, hubungan antar sampel diukur berdasarkan tingkat kesamaan yang direpresentasikan sebagai jarak.. Pada kasus mayoritas terutama pada data berukuran besar, akan terdapat beberapa sampel yang memiliki jarak yang sama namun amat mungkin tidak terpilih menjadi tetangga, maka pemilihan parameter k akan sangat mempengaruhi hasil klasifikasi kNN. Selain itu, pengurutan pada kNN menjadi masalah komputasi ketika dilakukan pada data berukuran besar. Dalam usaha mengatasi klasifikasi data berukuran besar dibutuhkan metode yang lebih akurat dan efisien. Dependent Nearest Neighbor (dNN) sebagai metode yang diajukan dalam penelitian ini tidak menggunakan parameter $\mathrm{k}$ dan tidak ada proses pengurutan sampel. Hasil percobaan menunjukkan bahwa dNN dapat menghasilkan efisiensi waktu sebesar 3 kali lipat lebih cepat daripada $\mathrm{kNN}$. Perbandingan akurasi dNN adalah 13\% lebih baik daripada kNN.
\end{abstract}

Kata kunci: klasifikasi, big data, nearest neighbor, data mining

\section{BIG DATA CLASSIFICATION EFFICIENCY USING IMPROVED NEAREST NEIGHBOR}

\begin{abstract}
Classification is one of the important methods of data mining. One of the most popular and basic classification methods is k-nearest neighbor $(k N N)$. In $k N N$, the relationships between samples are measured by the degree of similarity represented as distance. In major cases, especially on big data, there will be some samples that have the same distance but may not be selected as neighbors, then the selection of k parameters will greatly affect the results of kNN classification. Sorting phase of kNN becomes a computation problem when it is done on big data. In the effort to overcome the classification of big data a more accurate and efficient method is required. Dependent Nearest Neighbor (dNN) as method proposed in this study did not use the $k$ parameters and no sample at the sorting phase. The proposed method resulted in 3 times faster than $k N N$. The accuracy of the proposed method is $13 \%$ better results than $k N N$.
\end{abstract}

Keywords: classification, big data, nearest neighbor, data mining

\section{PENDAHULUAN}

Big data atau data berukuran besar adalah data yang didefinisikan menggunakan 5 karakteristik yaitu : volume, variety, velocity, veracity, dan value (Minelli, Chambers, \& Dhiraj, 2013). Seiring dengan bertambahnya karakteristik tersebut, maka beberapa metode tidak dapat menyimpan dan memproses data. Pada titik tersebut maka data tersebut dapat didefinisikan sebagai big data. Analisis big data didefinisikan sebagai proses pengamatan dan pemahaman terhadap karakteristik data dengan ukuran besar tersebut dengan tujuan mengekstrak pola-pola geometris dan statistik. Banyak aplikasi yang bermasalah dengan big data seperti lalu lintas, geospatial, bisnis, dan game.

Terdapat beberapa cara untuk melakukan analisis big data. Salah satu cara yang populer adalah data mining. Pada data mining terdapat banyak macam teknik seperti unsupervised dan supervised learning. Unsupervised learning digunakan untuk data yang tidak memperhatikan kelas didalamnya, sedangkan supervised learning memperhatikan kelas yang terlampir pada data. Pada supervised learning terdapat beberapa metode yaitu bayesian, neural network, support vector machine, decision tree, dan nearest neighbor. Salah satu metode yang populer adalah nearest neighbor classifier. Nearest neighbor 
classifier adalah metode yang menentukan kelas data berdasarkan kedekatan karakteristik dengan data lain. $\mathrm{K}$-nearest neighbor $(\mathrm{kNN})$ adalah nearest neighbor classifier yang melakukan voting penentuan kelas dengan tetangga sebanyak k. Kelemahan kNN adalah ketergantungan pada parameter $\mathrm{k}$ yang menyebabkan hasil yang berbeda pada setiap percobaan. Terdapat beberapa penelitian untuk meningkatkan performa nearest neighbor classifier. (Mullick, Datta, Das, \& Member, 2018) dan (Bohacik \& Zabovsky, 2017) melakukan penelitian terhadap metode learning $\mathrm{kNN}$. Sedangkan studi pada perhitungan jarak telah dilakukan oleh (Pan, Wang, \& Ku, 2017) (Neo \& Ventura, 2012) (Song, Liang, Lu, \& Zhao, 2017). Sedangkan penelitian untuk menggantikan parameter k sebagai tetangga terpilih dilakukan oleh (Ertuğrul \& Tağluk, 2017) dengan nama dependent nearest neighbor. Dependent nearest neighbor (dNN) adalah metode dengan menggunakan teori densitas untuk menentukan tetangga. Setiap data pada radius yang telah ditentukan akan langsung menjadi tetangga. Kelebihan dari metode $\mathrm{dNN}$ adalah menemukan hasil yang lebih baik dengan cara yang hampir sesederhana kNN namun menghindari kompleksitas perhitungan kNN agar dapat diimplementasikan pada big data.

Penelitian kNN pada big data telah dilakukan oleh (Cattral \& Oppacher, 2007) dengan poker hand dataset. Hasil yang diperoleh menggunakan tools Waikato Environment for Knowledge Analysis (WEKA) adalah 50.121\% dengan akurasi sebagai metode perhitungan performa. Tujuan dari penelitian ini adalah mengetahui performa metode yang diajukan dNN terhadap metode terdahulu yaitu kNN untuk memproses big data.

\section{METODOLOGI}

Langkah-langkah algoritma dNN adalah perhitungan dissimilarity, deteksi tetangga, pelabelan, dan evaluasi.

\subsection{Perhitungan Dissimilarity}

Jarak yang akan dihitung adalah jarak antar obyek data uji dengan seluruh data latih yang ada. Menurut (Han, Kamber, \& Pei, 2012), similarity adalah kuantitas yang mencerminkan hubungan antara dua obyek dengan fitur-fitur yang dimiliki. Sedangkan dissimilarity mengukur ketidaksesuaian obyek pada fitur yang dimiliki obyek tersebut. Semakin besar dissimilarity maka semakin besar pula jarak antar kedua obyek. Hubungan antara similarity dan dissimilarity akan ditunjukkan oleh persamaan 1 .

$$
\begin{array}{r}
\operatorname{Dissimilarity}(x, y)\left\{\begin{array}{l}
0,(x=y) \\
1,(x \neq y)
\end{array}\right. \\
\text { Similarity }=1-\text { Dissimilarity }
\end{array}
$$

Jika suatu fitur obyek $\mathrm{x}$ dan y bernilai sama, maka dissimilarity bernilai 0 , sebaliknya jika berbeda, maka dissimilarity bernilai 1. semakin berbeda nilai fitur-fitur antar obyek, maka dapat disimpulkan makin jauh jarak antar kedua obyek tersebut. Semakin jauh jarak sebuah onyek, semakin kecil pula kemungkinan sebuah obyek menjadi tetangga.

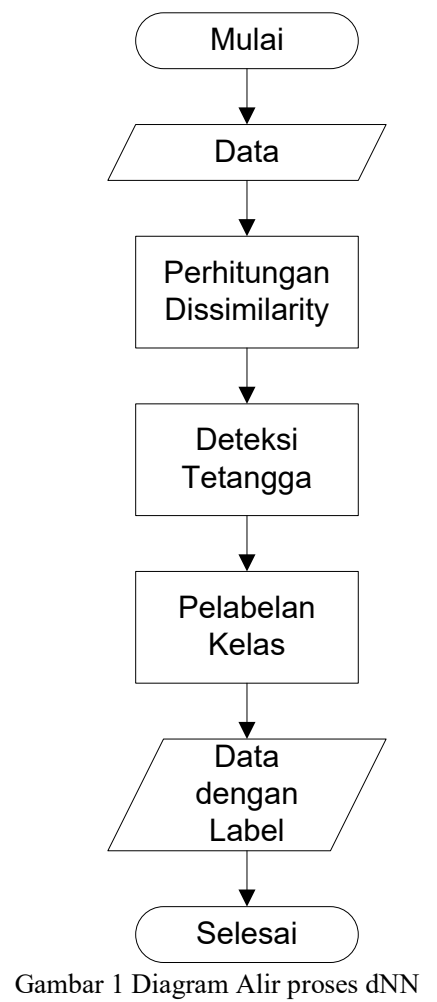

\subsection{Deteksi tetangga}

Setelah diketahui jarak antar obyek, maka tentukan tetangga dalam radius r. Ilustrasi penentuan tetangga akan ditunjukkan pada gambar 1 .

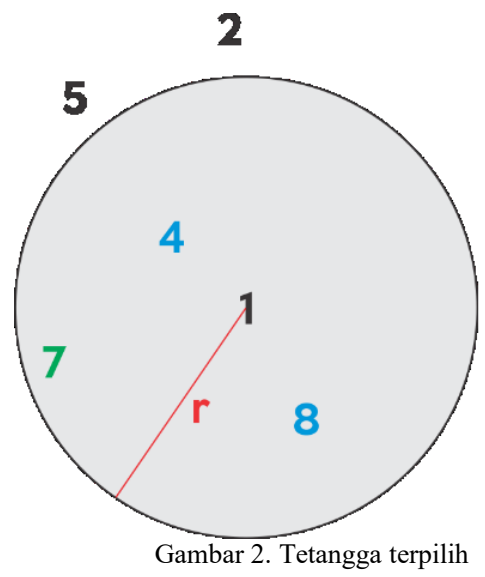

3

Jika diketahui data 1 adalah data uji, maka data 2 hingga 8 adalah data latih. Dalam radius $r$, data yang masuk adalah data 4, 8, dan 8, maka hanya ketiga data tersebut yang akan masuk pertimbangan pelabelan. Berbeda dengan $\mathrm{kNN}$, pada $\mathrm{kNN}$ jika dipilih $\mathrm{k}=3$, maka yang terpilih adalah 4,7 , dan 8 , namun jika $\mathrm{k}=4$, maka 4, 8, 7, dan 5 akan terpilih meskipun 5 berada cukup jauh dari 1 . hal ini adalah perbedaan mendasar dari kNN dan dNN. 


\subsection{Pelabelan}

Metode pelabelan yang akan digunakan pada dNN sama dengan kNN yaitu dengan modus kelas tetangga. Kelas yang paling banyak muncul dari tetangga yang terpilih akan ditetapkan sebagai predicted class data uji tersebut. Predicted class akan dibandingkan dengan actual class pada fase evaluasi. Berdasarkan gambar 1, contoh pelabelan akan ditunjukkan oleh tabel 1 .

Tabel 1. Distribusi tetangga

\begin{tabular}{cc}
\hline Data & Kelas \\
\hline 4 & Biru \\
\hline 8 & Biru \\
\hline 7 & Hijau \\
\hline
\end{tabular}

Pada Tabel 1 dapat diketahui bahwa kelas biru adalah kelas yang paling sering muncul, maka dari itu predicted class untuk data 1 adalah biru. Jika terdapat jumlah kelas yang sama pada distribusi tetangga, maka pilih salah satu dari kelas-kelas tersebut.

Tabel 2 Distribusi tetangga dengan jumlah anggota kelas yang

\begin{tabular}{cc} 
& sama \\
\hline Data & Kelas \\
\hline 4 & Biru \\
\hline 8 & Biru \\
\hline 7 & Hijau \\
\hline 5 & Hijau \\
\hline 2 & Merah
\end{tabular}

Sebagai contoh pada Tabel 2, jika terdapat dua kelas biru dan dua kelas hijau. Pilih salah satu diantara keduanya dengan cara acak.

\subsection{Evaluasi}

Pada fase evaluasi, metode yang digunakan adalah f-measure. F-measure adalah metode untuk mengukur relevansi suatu kelas dengan hasil prediksi. Sebelum dilakukan perhitungan f-measure, data akan dibentuk dengan confusion matrix terlebih dahulu. Contoh tabel confusion matrix akan ditunjukkan oleh tabel 3 .

Tabel 3. Confusion Matrix

\begin{tabular}{c|c|c|c}
\hline & \multicolumn{3}{c}{ Actual Class } \\
\hline \multirow{3}{*}{$\begin{array}{c}\text { Predicted } \\
\text { Class }\end{array}$} & Biru & Biru & Lain \\
\cline { 2 - 4 } & Lain & $3 \mathrm{FP}$ & $2 \mathrm{FP}$ \\
\hline
\end{tabular}

Dengan persamaan sebagai berikut :

$$
\begin{aligned}
& \text { Precision }=\frac{T P}{T P+F P} \\
& \text { Recall }=\frac{T P}{T P+F N} \\
& F-\text { Measure }=\frac{2 * \text { Precision } * \text { Recall }}{\text { Precision }+ \text { Recall }}
\end{aligned}
$$

\subsection{Dataset}

Dataset yang digunakan adalah Poker hand dataset yang disediakan oleh UCI Machine Learning Repository. Dataset poker hand adalah salah satu dataset yang menantang untuk klasifikasi . Setiap kartu diambil dari dek standar berisikan 52 kartu. Setiap kartu direpresentasikan oleh dua atribut (suit dan rank), untuk total 10 atribut prediktif. Ada satu atribut kelas yang menggambarkan "Poker Hand". Urutan kartu penting dan diperhitungkan. Salah satu pertimbangan dalam penggunaan dataset ini adalah pada penelitian sebelumnya oleh Ertuğrul (2017) tidak terdapat data yang berukuran besar. Berikut adalah informasi tentang Poker Hand dataset.

\begin{tabular}{ll}
\multicolumn{2}{c}{ Tabel 4. Informasi Dataset Poker Hand } \\
\hline Instance & $\begin{array}{c}25010 \text { data latih } \\
1000000 \text { data uji }\end{array}$ \\
\hline Atribut & 10 prediktif \\
& 0 \\
\hline Missing value & (kelas) \\
\hline Distribusi kelas data latih & \\
0: Nothing in hand, 12493 instance \\
1: One pair, 10599 instance \\
2: Two pairs, 1206 instance \\
3: Three of a kind, 513 instance \\
4: Straight, 93 instance \\
5: Flush, 54 instance \\
6: Full house, 36 instance \\
7: Four of a kind, 6 instance \\
8: Straight flush, 5 instance \\
9: Royal flush, 5 instance \\
\hline Distribusi kelas data uji \\
0: Nothing in hand, 501209 instance \\
1: One pair, 422498 instance \\
2: Two pairs, 47622 instance \\
3: Three of a kind, 21121 instance \\
4: Straight, 3885 instance \\
5: Flush, 1996 instance \\
6: Full house, 1424 instance \\
7: Four of a kind, 230 instance \\
8: Straight flush, 12 instances \\
9: Royal flush, 3 instances \\
\hline
\end{tabular}

Pada tabel 4 dapat diketahui bahwa dataset poker hand memiliki distribusi yang tidak merata pada setiap kelas. Jeda antara jumlah kelas terkecil dan terbesar terpaut 5-12493 instance untuk data latih dan 3-501209 instance untuk data uji. Perbedaan jumlah instance tiap kelas yang tidak merata amat memungkinkan kesalahan klasifikasi. Sedangkan jumlah data yang besar akan menguji efisiensi metode dalam hal komputasi.

\section{ANALISIS HASIL}

Skenario pengujian yang dilakukan adalah menjalankan $\mathrm{dNN}$ dan $\mathrm{kNN}$ dengan parameter masing-masing. Pada kNN, k yang akan digunakan adalah 1 hingga 10 dan pada dNN radius yang akan digunakan adalah 0,1 hingga 1 . Ketika pengujian parameter sudah dilakukan, kemudian dilanjutkan dengan pengujian persentase data latih. Data latih yang akan diujikan adalah $25 \%$ dan $50 \%$ menggunakan parameter terbaik dari pengujian sebelumnya. Dengan demikian hasil yang akan 
didapat adalah f-measure dan running time dari aplikasi tersebut.

Aplikasi dibuat dengan Visual Studio 2017, dengan bahasa pemrograman C\#. Aplikasi dijalankan pada PC dengan spesifikasi i7 haswell, 8GB Ram, VGA R9 285, dan harddisk 1TB.

Berikut ini adalah hasil dari pengujian :

Tabel 5. Perbandingan f-measure data latih 100\%

\begin{tabular}{cc|cc}
\hline \multicolumn{1}{l}{$\mathbf{k N N}$} & \multicolumn{2}{c}{ dNN } \\
\hline $\mathbf{k}$ & $\mathbf{f}$-measure & $\mathbf{r} \%$ & $\mathbf{f}$-measure \\
\hline $\mathbf{1}$ & 0.158342 & $\mathbf{1}$ & 0.166176 \\
\hline $\mathbf{2}$ & 0.158342 & $\mathbf{2}$ & 0.166176 \\
\hline $\mathbf{3}$ & 0.159833 & $\mathbf{3}$ & 0.166176 \\
\hline $\mathbf{4}$ & 0.155109 & $\mathbf{4}$ & 0.166176 \\
\hline $\mathbf{5}$ & 0.155667 & $\mathbf{5}$ & 0.166176 \\
\hline $\mathbf{6}$ & 0.150426 & $\mathbf{6}$ & 0.166176 \\
\hline $\mathbf{7}$ & 0.144385 & $\mathbf{7}$ & 0.166176 \\
\hline $\mathbf{8}$ & 0.141193 & $\mathbf{8}$ & 0.166176 \\
\hline $\mathbf{9}$ & 0.138241 & $\mathbf{9}$ & 0.166176 \\
\hline $\mathbf{1 0}$ & 0.134343 & $\mathbf{1 0}$ & 0.166176
\end{tabular}

Tabel 6. Perbandingan f-measure data latih 50\%

\begin{tabular}{cc|cc}
\hline \multicolumn{2}{c}{$\mathbf{k N N}$} & \multicolumn{2}{c}{$\mathbf{d N N}$} \\
\hline $\mathbf{k}$ & $\mathbf{f - m e a s u r e}$ & $\mathbf{r} \%$ & $\mathbf{f}$-measure \\
\hline 1 & 0.129337465 & 1 & 0.1475516 \\
\hline 2 & 0.129337465 & 2 & 0.1534084 \\
\hline 3 & 0.139181782 & 3 & 0.1534084 \\
\hline 4 & 0.147634358 & 4 & 0.1534084 \\
\hline 5 & 0.148077823 & 5 & 0.1534084 \\
\hline 6 & 0.145030803 & 6 & 0.1534084 \\
\hline 7 & 0.138620978 & 7 & 0.1534084 \\
\hline 8 & 0.131786414 & 8 & 0.1534084 \\
\hline 9 & 0.126279548 & 9 & 0.1534084 \\
\hline 10 & 0.122452683 & 10 & 0.1534084 \\
\hline
\end{tabular}

Tabel 7. Perbandingan f-measure data latih $25 \%$

\begin{tabular}{cc|cc}
\hline \multicolumn{1}{c}{$\mathbf{k N N}$} & \multicolumn{2}{c}{$\mathbf{d N N}$} \\
\hline $\mathbf{k}$ & $\mathbf{f - m e a s u r e}$ & $\mathbf{r} \%$ & $\mathbf{f}$-measure \\
\hline 1 & 0.122727878 & 1 & 0.153408 \\
\hline 2 & 0.122727878 & 2 & 0.147552 \\
\hline 3 & 0.129692838 & 3 & 0.147552 \\
\hline 4 & 0.136140314 & 4 & 0.147552 \\
\hline 5 & 0.135835685 & 5 & 0.147552 \\
\hline 6 & 0.134581623 & 6 & 0.147552 \\
\hline 7 & 0.135206896 & 7 & 0.147552 \\
\hline 8 & 0.139272028 & 8 & 0.147552 \\
\hline 9 & 0.145190208 & 9 & 0.147552 \\
\hline 10 & 0.149933762 & 10 & 0.147552 \\
\hline
\end{tabular}

Pada perbandingan performa klasifikasi, dNN lebih unggul pada semua ukuran data latih. Pada Tabel 5 dataset $100 \%$ dNN lebih unggul $11,4 \%$ dibandingkan $\mathrm{kNN}$, pada Tabel 6 dataset $50 \%$ dNN lebih unggul $13 \%$, dan pada Tabel 7 dataset $25 \%$ dNN lebih unggul $10 \%$. Hasil tersebut membuktikan bahwa dNN lebih unggul dari segi performa untuk berbagai macam ukuran data. Performa dNN cenderung lebih stabil, namun performa $\mathrm{dNN}$ memburuk pada parameter $\mathrm{r}$ yang besar, ditunjukkan pada Tabel 8.

Tabel 8. Perbandingan performa $\mathrm{dNN}$ pada parameter $\mathrm{r}$

\begin{tabular}{cccc}
\hline $\mathrm{r} \%$ & match & f-measure & waktu (jam) \\
\hline 10 & 527068 & 0.1661759 & 2.769603611 \\
\hline 20 & 565175 & 0.1286764 & 2.9746616667 \\
\hline 30 & 543550 & 0.0975356 & 2.7839280556 \\
\hline 40 & 536494 & 0.0906148 & 2.8078872222 \\
\hline 50 & 502045 & 0.0674232 & 2.9892316667 \\
\hline
\end{tabular}

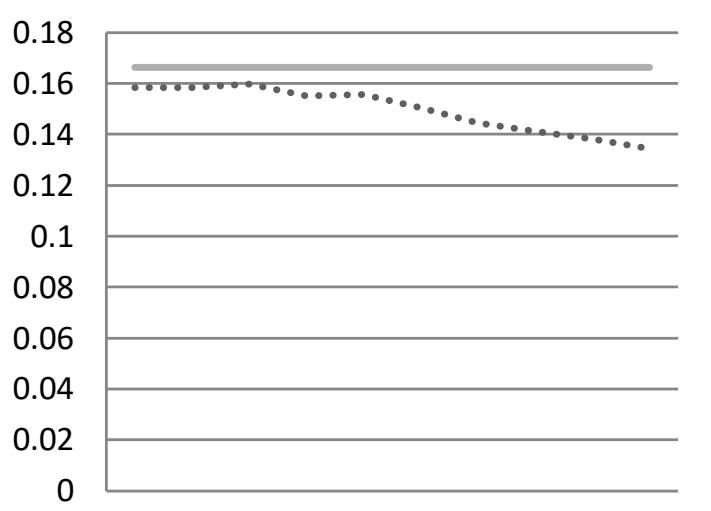

$\begin{array}{llllllllll}1 & 2 & 3 & 4 & 5 & 6 & 7 & 8 & 9 & 10\end{array}$

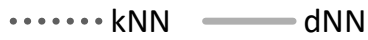

Gambar 3. Grafik Perbandingan f-Measure dNN dan kNN

Hasil pada Tabel 8 menunjukkan bahwa dNN baik digunakan pada parameter $r$ kurang dari 10 . Penggunaan parameter $r$ lebih dari itu kurang direkomendasikan, karena makin banyak sampel yang tidak relevan masuk menjadi tetangga.

Tabel 9. Perbandingan waktu pada data latih $100 \%$

\begin{tabular}{cc|cc}
\hline \multicolumn{2}{l}{ kNN } & \multicolumn{2}{c}{$\mathbf{d N N}$} \\
\hline $\mathbf{k}$ & waktu (jam) & $\mathbf{r \%}$ & waktu (jam) \\
\hline 1 & 8.845525 & 1 & 3.277773 \\
\hline 2 & 9.281101 & 2 & 2.697624 \\
\hline 3 & 9.689663 & 3 & 3.077514 \\
\hline 4 & 11.01999 & 4 & 2.997817 \\
\hline 5 & 10.17192 & 5 & 2.886226 \\
\hline 6 & 11.39882 & 6 & 2.974662 \\
\hline 7 & 11.57956 & 7 & 2.783928 \\
\hline 8 & 11.76181 & 8 & 2.807887 \\
\hline 9 & 11.01212 & 9 & 2.989232 \\
\hline 10 & 12.16621 & 10 & 2.769604 \\
\hline
\end{tabular}


Tabel 10. Perbandingan waktu pada data latih 50\%

\begin{tabular}{cc|cc}
\hline \multicolumn{1}{l}{$\mathbf{k N N}$} & \multicolumn{2}{c}{ dNN } \\
\hline $\mathbf{k}$ & waktu (jam) & $\mathbf{r \%}$ & waktu (jam) \\
\hline 1 & 2.390273 & 1 & 1.382309 \\
\hline 2 & 2.405384 & 2 & 1.359527 \\
\hline 3 & 2.493089 & 3 & 1.362739 \\
\hline 4 & 2.680436 & 4 & 1.387331 \\
\hline 5 & 2.743325 & 5 & 1.387698 \\
\hline 6 & 2.766918 & 6 & 1.366829 \\
\hline 7 & 2.910411 & 7 & 1.387539 \\
\hline 8 & 3.0323 & 8 & 1.383196 \\
\hline 9 & 3.075043 & 9 & 1.387854 \\
\hline 10 & 3.156808 & 10 & 1.358761 \\
\hline
\end{tabular}

Tabel 11. Perbandingan waktu pada data latih $25 \%$

\begin{tabular}{cc|cc}
\hline \multicolumn{2}{l}{ kNN } & \multicolumn{2}{c}{ dNN } \\
\hline $\mathbf{k}$ & waktu (jam) & $\mathbf{r \%}$ & waktu (jam) \\
\hline 1 & 1.510839 & 1 & 1.521357 \\
\hline 2 & 1.560573 & 2 & 1.420285 \\
\hline 3 & 1.650828 & 3 & 1.321135 \\
\hline 4 & 1.795513 & 4 & 1.657194 \\
\hline 5 & 1.944818 & 5 & 1.52047 \\
\hline 6 & 2.017786 & 6 & 1.325304 \\
\hline 7 & 2.075959 & 7 & 1.529306 \\
\hline 8 & 2.136557 & 8 & 1.451279 \\
\hline 9 & 2.279071 & 9 & 1.393115 \\
\hline 10 & 2.436634 & 10 & 1.466805 \\
\hline
\end{tabular}

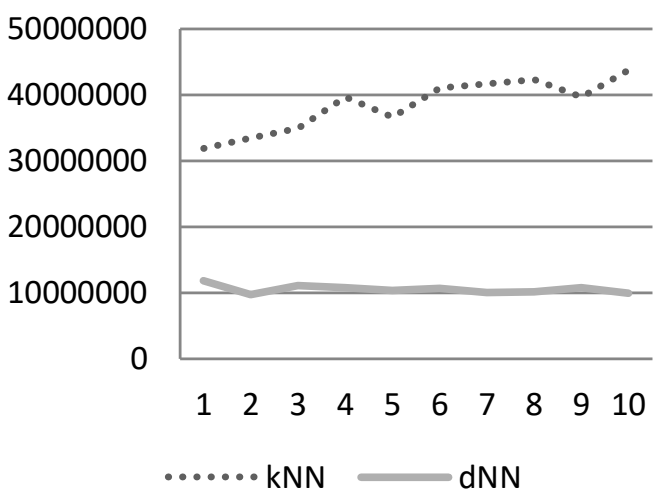

Gambar 4. Grafik Perbandingan Running Time

dNN cenderung berjalan dengan waktu yang lebih cepat. Pada Tabel 11 dataset $25 \%$ kNN menempuh waktu $169 \%$ lebih lama dari dNN, pada Tabel $10 \mathrm{kNN}$ lebih 223\% lebih lama daripada dNN, sedangkan pada Tabel 9 kNN lebih 339\% lebih lama daripada dNN. Hal ini disebabkan karena dNN tidak memerlukan sorting seperti pada kNN. Proses sorting pada big data sebaiknya dihindari, karena sorting cenderung memiliki komputasi kuadratik. Salah satu cara untuk mengatasi masalah sorting pada kNN adalah partial sorting dan sudah diimplementasikan pada penelitian ini. Contoh perhitungan pada 1 data uji dengan 25100 data latih adalah sebagai berikut.
Tabel 11 akan menunjukkan perbandingan komputasi $\mathrm{dNN}$ dan $\mathrm{kNN}$.

Tabel 12. Perbandingan Komputasi dNN vs kNN

\begin{tabular}{|c|c|}
\hline $\mathrm{kNN}$ dengan $\mathrm{k}=3$ & Komputasi \\
\hline $\begin{array}{l}\text { Scan semua data latih, ambil } \\
\text { data latih yang berjarak paling } \\
\text { kecil sebanyak k. }\end{array}$ & $\begin{array}{c}25100+ \\
25099+ \\
25098=75297\end{array}$ \\
\hline $\begin{array}{l}\text { Scan k tetangga untuk melihat } \\
\text { kelas yang akan dipilih. }\end{array}$ & 3 \\
\hline Jumlah & 75300 \\
\hline dNN dengan $r=3$ & Komputasi \\
\hline $\begin{array}{l}\text { Scan semua data latih, ambil } \\
\text { semua data latih yang berada } \\
\text { pada } r=3\end{array}$ & 25100 \\
\hline $\begin{array}{l}\text { Scan semua tetangga untuk } \\
\text { melihat kelas mana yang akan } \\
\text { dipilih (asumsi tetangga terpilih } \\
\text { adalah 50) }\end{array}$ & 50 \\
\hline Jumlah & 25150 \\
\hline
\end{tabular}

Dari perhitungan pada tabel 12 dapat disimpulkan bahwa dNN lebih efisien karena tidak menggunakan sorting pada waktu memproses. dNN terbukti dapat melakukan performa $75300 / 25150=$ $299.4 \%$, artinya 3 kali lebih cepat daripada $\mathrm{kNN}$. Perbandingan tersebut dapat lebih mencolok ketika data uji yang diproses berjumlah besar. Pada dataset poker hand yang memiliki 1000000 instance, sangat mungkin kNN melakukan komputasi $1000000 * 75300$ pada $\mathrm{k}=3$. Jika $\mathrm{k}$ yang dipilih lebih besar, sudah tentu akan berdampak pada komputasi yang harus dilakukan. dNN tidak memiliki beban sorting seperti kNN menyebabkan stabilitas performa dNN untuk data berukuran besar.

\section{KESIMPULAN}

Penelitian ini menunjukkan bahwa metode nearest neighbor dapat digunakan untuk melakukan analisis big data. $\mathrm{kNN}$ adalah metode nearest neighbor paling sederhana namun dapat menganalisa big data. kNN memiliki kelemahan menentukan parameter $\mathrm{k}$ yang terbaik namun untuk menemukan $\mathrm{k}$ terbaik adalah proses yang sangat memakan waktu. Untuk mengatasi hal tersebut digunakan metode dNN yang tidak menggunakan parameter $\mathrm{k}$, melainkan menggunakan radius yang berhasil berjalan dengan performa yang amat baik. Running time yang dihasilkan metode $\mathrm{dNN}$ lebih cepat daripada $\mathrm{kNN}$ karena dNN tidak menggunakan sorting secara berlebihan. Meskipun dNN memiliki performa yang baik untuk klasifikasi dataset poker hand, namun hasil yang didapatkan masih bisa ditingkatkan lagi dengan perbaikan metode dan running time bisa diturunkan dengan metode lain.

\section{DAFTAR PUSTAKA}

BOHACIK, J., \& ZABOVSKY, M. 2017. Nearest Neighbor Method Using Non-nested 
Generalized Exemplars in Breast Cancer Diagnosis, 40-44.

CATTRAL, R., \& OPPACHER, F. 2007. Discovering rules in the poker hand dataset. Proceedings of the 9th Annual Conference on Genetic and Evolutionary Computation GECCO '07, (May), 1870. https://doi.org/10.1145/1276958.1277329

ERTUĞRUL, Ö. F., \& TAĞLUK, M. E. 2017. A novel version of $\mathrm{k}$ nearest neighbor: Dependent nearest neighbor. Applied Soft Computing Journal, 55, 480-490. https://doi.org/10.1016/j.asoc.2017.02.020

HAN, J., KAMBER, M., \& PEI, J. 2012. Data Mining: Concepts and Techniques. San Francisco, CA, itd: Morgan Kaufmann. https://doi.org/10.1016/B978-0-12-3814791.00001-0

MINELLI, M., CHAMBERS, M., \& DHIRAJ, A. 2013. Big Data Analytics - Emerging BI and Analitics trends for today's businesses.

MULliCK, S. S., DATTA, S., DAS, S., \& MEMBER, S. 2018. Adaptive Learning-Based k -Nearest Neighbor Classifiers With Resilience to Class Imbalance, 1-13.

NEO, T. K. C., \& VENTURA, D. 2012. A direct boosting algorithm for the k-nearest neighbor classifier via local warping of the distance metric. Pattern Recognition Letters, 33(1), 92102. https://doi.org/10.1016/j.patrec.2011.09.028

PAN, Z., WANG, Y., \& KU, W. 2017. A new general nearest neighbor classification based on the mutual neighborhood information. KnowledgeBased Systems, 121, 142-152. https://doi.org/10.1016/j.knosys.2017.01.021

SONG, Y., LIANG, J., LU, J., \& ZHAO, X. 2017. An efficient instance selection algorithm for $\mathrm{k}$ nearest neighbor regression. Neurocomputing, 251, 26-34. https://doi.org/10.1016/j.neucom.2017.04.018 